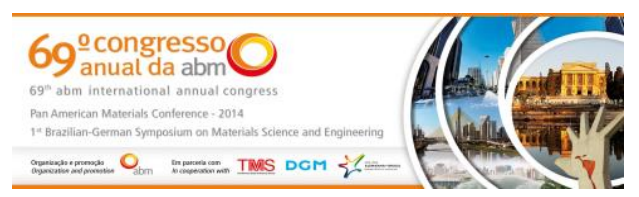

Tema: Gestão de meio ambiente, recuperação e tratamento de rejeitos

\title{
CARACTERIZAÇÃO DE PLACA DE CIRCUITO IMPRESSO PROVENIENTE DE COMPUTADORES OBSOLETOS VISANDO PROCESSAMENTO BIOHIDROMETALÚRGICO*
}

\section{Resumo}

\author{
Carlos Gonzalo Alvarez Rosario \\ Gabriella Morelli Vezzá \\ Flávia Paulucci Cianga Silvas ${ }^{3}$ \\ Viviane Tavares de Moraes ${ }^{4}$ \\ Denise Crocce Romano Espinosa ${ }^{5}$ \\ Jorge Alberto Soares Tenório ${ }^{6}$
}

A reciclagem de resíduos eletroeletrônicos (REEs) é importante tanto no aspecto ambiental quanto econômico, uma vez que através do reaproveitamento do REE há diminuição da quantidade de resíduos a ser destinados, além disso, contribui para a sustentabilidade do setor minero metalúrgico, pois é possível a recuperação dos metais provenientes de REEs. Presentes na maioria dos equipamentos eletroeletrônicos, as Placas de Circuito Impresso (PCls) são compostas por materiais cerâmicos, metálicos e poliméricos. Além disso, a heterogeneidade do material influi diretamente no tipo de processamento/tratamento a ser utilizado, desta forma a caracterização prévia do resíduo é uma etapa fundamental para determinação da rota de processamento a ser utilizada. Assim, no presente estudo é apresentado o processo de caracterização de PCls proveniente de computadores obsoletos objetivando a determinação e quantificação dos metais presentes, de forma a estudar a influência dos mesmos em processos de biolixiviação futuros. A rota de processamento físico incluiu inicialmente processo manual utilizando guilhotina e, posteriormente, moinho de martelos com grelhas de aberturas de $6 \mathrm{~mm}$ e $2 \mathrm{~mm}$. A caracterização foi realizada através de ensaios de perda ao fogo, lixiviação ácida e MEV/EDS e a concentração dos metais foi determinada por ICP-OES. Os resultados mostraram que $50 \%$ do material particulado tem granulometria maior que $0,25 \mathrm{~mm}$; as PCls estudadas possuem $35,6 \%$ de metais, $27,2 \%$ de polímeros e $37,2 \%$ de cerâmicos. Dos metais presentes nas placas o mais representativo foi o cobre com 21,4\% em massa enquanto que metais como Fe e Al apresentaram 1,1\% e 1,9\% em massa.

Palavras-chave: Reciclagem; Placa de circuito impresso; Resíduo eletroeletrônico.

\section{CHARACTERIZATION OF PRINTED CIRCUIT BOARD FROM SCRAP COMPUTER AIMING BIOHYDROMETALURGICAL PROCESS}

\begin{abstract}
The recycle of e-waste is not only important in the environmental aspect but also in the economic, once through the e-waste's reuse there is a decrease on the quantity of waste to be stored. Furthermore, it contributes to the sustainability of the metallurgical mineral sector because it allows the recovery of metals from e-waste. The printed circuit boards are found on most of the electronic devices and are made of ceramic, metallic and polymeric materials. Further, the material's heterogeneity directly influences on the type of process/treatment to be used and that is why the previous characterization of the waste is a fundamental step to determine the best processing route to use. So in this present study it is presented the comminution process and the characterization of printed circuit boards from outdated computers aiming to determine and qualify the present metals to study their influence on the bioleaching processes. The physical processing route included, first of all, manual process using cutter and, thereafter, hammer mill with two different sizes of grids $(6 \mathrm{~mm}$ and $2 \mathrm{~mm})$. Testing loss to fire, acid leaching and microscopy performed the characterization and the metal's concentration was determined by ICP-OES. The results show that half of the particulate material is smaller than $0,5 \mathrm{~mm}$; the PCBs studied have $35,6 \%$ of metals, $27,2 \%$ of polymers and $37,2 \%$ of ceramics. The most representative metal present on the PCBs, comparing to the others, was copper with $21,4 \%$ by weight whereas metals such as iron and aluminum present $1,1 \%$ and $1,9 \%$ by weight.

Keywords: Recycling; Printed circuit board; Electrical and electronic waste.

\footnotetext{
${ }^{1}$ Mestre em Engenharia Civil, Doutorando, Engenharia Metalúrgica e de Materiais, Escola Politécnica, USP, São Paulo, SP, Brasil.

2 Graduanda, engenharia Metalúrgica e de Materiais, Escola Politécnica, USP, São Paulo, SP, Brasil.

${ }^{3}$ Mestre em Engenharia Metalúrgica, Doutoranda em engenharia Metalúrgica e de Materiais, Escola Politécnica, USP, São Paulo, $S P$, Brasil.

4 Dra. e Pós-doutoranda, Engenharia Metalúrgica e de Materiais, Escola Politécnica, USP, São Paulo, SP, Brasil.

5 Dra., Engenharia Metalúrgica e de Materiais, Prof. Associada, Escola Politécnica, USP, São Paulo, SP, Brasil.

${ }^{6}$ Dr. em Engenharia Metalúrgica e de Materiais, Prof. Titular, Escola Politécnica, USP, São Paulo, SP, Brasil.
}

\footnotetext{
* Contribuição técnica ao 69ํ Congresso Anual da ABM - Internacional e ao 14ํㅡㄹ ENEMET - Encontro Nacional de Estudantes de Engenharia Metalúrgica, de Materiais e de Minas, 21 a 25 de julho de 2014, São Paulc Brasil.
} 


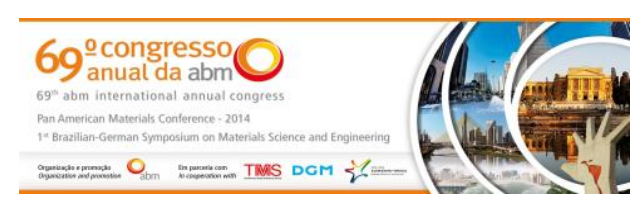

\section{INTRODUÇÃO}

Com o rápido avanço da tecnologia e constante aperfeiçoamento de computadores e celulares, os equipamentos eletrônicos tem se tornado obsoletos em um período, muitas vezes, inferior a dois anos, o que leva a uma geração excessiva de resíduo eletroeletrônico [1].

Segundo estudos do IBGE realizados em 2010, aproximadamente $64 \%$ dos municípios brasileiros depositavam seus resíduos eletroeletrônicos em lixões a céu aberto e sem nenhum tratamento. O problema está no fato de que a exposição a intempéries facilita a lixiviação e consequente solubilização da fração metálica presente nestes resíduos, podendo contaminar o solo e lençol freático [2,3].

Além dos problemas socioambientais originados pela destinação, muitas vezes incorreta, dos REEs, há também fatores econômicos envolvidos no processo gestão deste resíduo, uma vez que com o descarte são desperdiçados metais e outros materiais com valor agregado. Assim, através de processos de reciclagem é possível a recuperação da fração metálica dos REEs implicando numa menor exploração de jazidas, muitas já esgotadas, e também na economia energética, uma vez que 0 metal já se encontra na forma metálica [4].

As placas de circuito impresso são componentes básicos presentes em quase todos equipamentos eletroeletrônicos e, em geral, tem em sua composição $30 \%$ de plásticos, como polietileno, polipropileno, poliésteres e policarbonetos, além de plásticos halogenados, $30 \%$ de óxidos refratários, como a sílica, alumina, óxidos alcalino e alcalino-terrosos e o restante são metais, que podem ser divididos em metais base e metais preciosos. Os primeiros são cobre, ferro, estanho, níquel, alumínio, chumbo e zinco e os preciosos, que aparecem em menor quantidade, são prata, ouro e paládio [5].

Apesar desses dados, a composição de uma placa pode variar muito, tanto de acordo com a finalidade do equipamento a ser montado quanto à tecnologia, isto é, verifica-se que computadores mais antigos, por exemplo, apresentavam uma grande quantidade de chumbo, que foi sendo substituída, gradativamente, por prata e bismuto. Devido a essa heterogeneidade, a caracterização da placa é de extrema importância para definição das melhores técnicas e processos a serem utilizados para a reciclagem [6].

Dentre as tecnologias empregadas tem-se a biolixiviação. Este é um processo que faz uso de microrganismos para solubilizar metais e apresenta vantagem quando comparado a outros processos pela economia de insumos, por não emitir poluentes gasosos e apresentar baixo custo e baixo consumo energético. Muitos são os fatores que interferem na biolixiviação, dentre eles, a concentração de íons metálicos no lixiviado, uma vez que essa concentração, se muito elevada, pode ser tóxica à bactéria. Metais como a prata, o níquel, ouro, chumbo e zinco, por exemplo, quando em concentrações muito elevadas, podem intoxicar o microrganismo. Essas concentrações máximas variam de um microrganismo para outro. Além disso, a composição do material e o tamanho da partícula também são fatores a serem considerados na escolha do microrganismo que resista às concentrações de certas substancias presentes na placa e que seja efetivo na solubilização do(s) metal(is) de interesse, além de auxiliar na definição dos parâmetros a serem empregados durante o processo de biolixiviação [7].

Deste modo, o objetivo do presente trabalho é a caracterização de PCls provenientes de computadores obsoletos visando a futura utilização em processos de biolixiviação.

* Contribuição técnica ao 69 Congresso Anual da ABM - Internacional e ao 14ํㅡㄹ ENEMET - Encontro Nacional de Estudantes de Engenharia Metalúrgica, de Materiais e de Minas, 21 a 25 de julho de 2014, São Paulo, SP, Brasil. 


\section{MATERIAIS E MÉTODOS}

Para os ensaios foram utilizadas PCl's provenientes de computadores obsoletos coletados junto ao CEDIR (Centro de Descarte e Reuso de Resíduos de Informática).

Na Figura 1 tem-se o fluxograma das etapas utilizadas neste estudo.

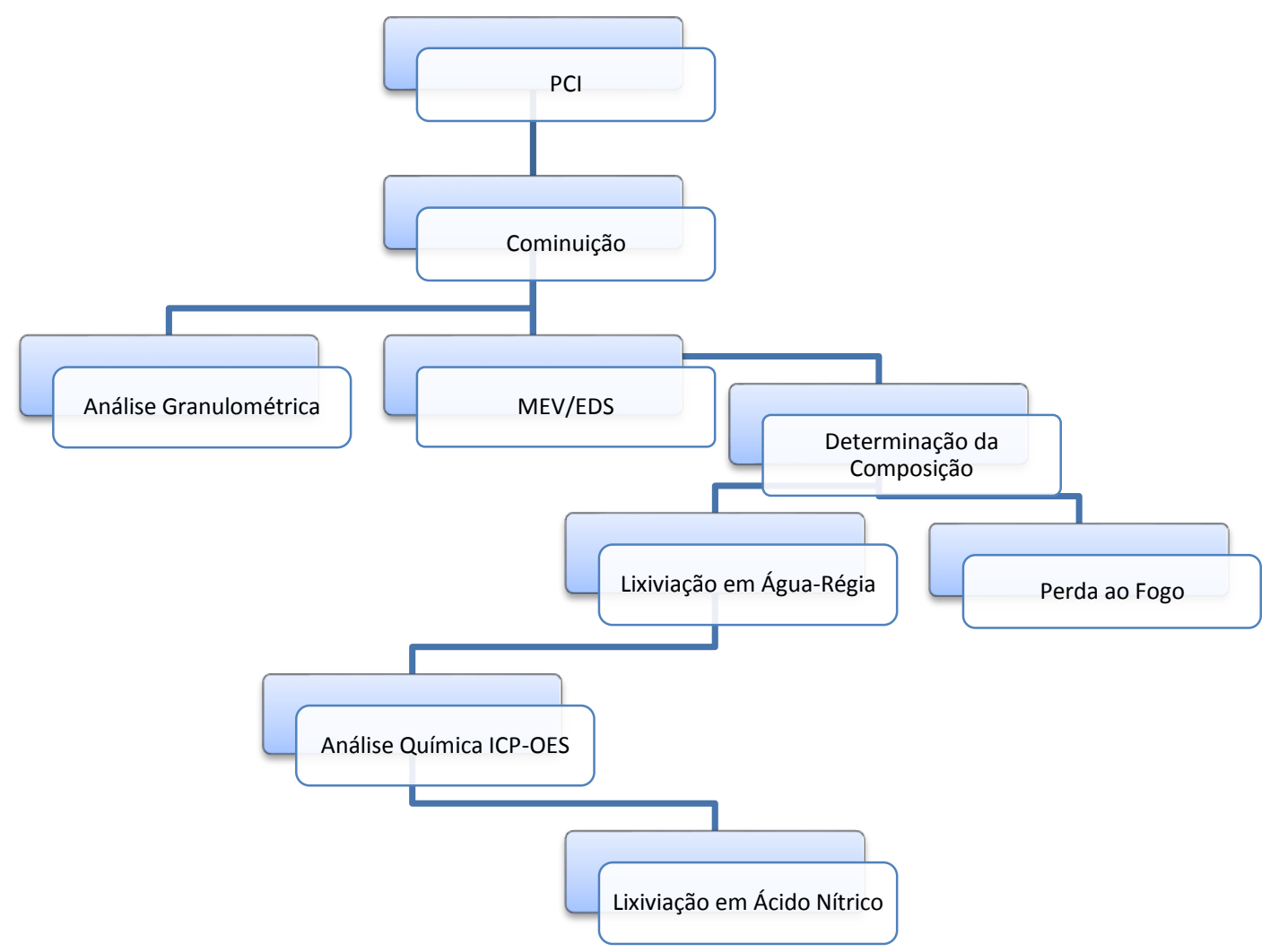

Figura 1. Fluxograma do processo

\subsection{Cominuição}

A cominuição foi feita em três etapas. Na primeira, peças como baterias, capacitores e demais componentes foram retiradas manualmente com o auxílio de alicates antes do processamento físico propriamente dito. Em um segundo estágio, uma guilhotina manual foi utilizada e as placas de circuito impresso foram cortadas com aproximadamente $18 \times 28 \mathrm{~cm}$ de tamanho (medida aproximada da abertura de alimentação do equipamento utilizado). Na terceira etapa, um moinho de martelos modelo MDM 18/18 da marca Astecma foi utilizado para reduzir o tamanho das placas. Foram utilizadas duas grelhas: inicialmente uma de $6 \mathrm{~mm}$ e em seguida de 2 $\mathrm{mm}$ de abertura.

\subsection{Análise Granulométrica}

Tendo em vista que as PCls são amostras heterogêneas, para minimizar os erros, quarteou-se previamente a amostra antes da análise granulométrica. Aproximadamente $4 \mathrm{~kg}$ de PCls já cominuidas foram quarteadas segundo norma ABNT NBR 10007:2004 [8] e separadas em amostras de 5 gramas.

* Contribuição técnica ao 69 Congresso Anual da ABM - Internacional e ao 14ํㅡㄹ ENEMET - Encontro Nacional de Estudantes de Engenharia Metalúrgica, de Materiais e de Minas, 21 a 25 de julho de 2014, São Paulo, SP, Brasil. 


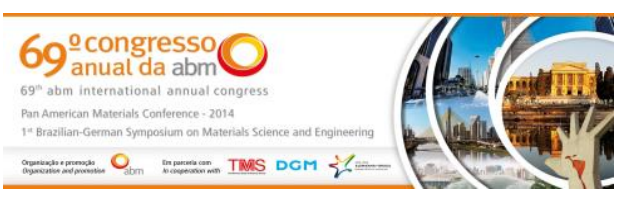

A amostra foi classificada por peneiramento durante 20 minutos, sob agitação em peneiras vibratórias com as seguintes aberturas: $4 \mathrm{~mm}, 2 \mathrm{~mm}, 1 \mathrm{~mm}, 0,5 \mathrm{~mm}, 0,25$ $\mathrm{mm}, 0,125 \mathrm{~mm}, 0,075 \mathrm{~mm}$ e $0,038 \mathrm{~mm}$. As peneiras, assim como a base, foram pesadas antes e após o peneiramento a fim de calcular a massa retida em cada faixa granulométrica.

\subsection{MEV/ EDS}

Selecionou-se diversos pedaços de diferentes tipos de placa para análise em microscópio eletrônico de varredura (MEV) equipado com sistema de dispersão de energia (EDS) a fim de analisar o número de camadas da placa e sua composição química. As amostras foram previamente recobertas com ouro já que não são condutoras de eletricidade.

As placas podem ser classificadas como mono layer, isto é, apresentam somente uma face da placa revestida de cobre (placas mais antigas), dual layer, apresentam as duas faces da placa revestida de cobre e multi layer, que são aquelas com várias camadas de cobre entre fibras de vidro $[1,6]$. Assim, a análise microscópica é feita para verificar a quantidade de camadas das placas e sua composição

\subsection{Lixiviação em Meio Ácido}

Os ensaios de lixiviação em meio acido foram divididos em duas etapas:

$\rightarrow \mathrm{Na}$ primeira etapa as placas de circuito impresso cominuidas, foram solubilizadas em água régia e posteriormente foi feita a filtragem da solução obtendo assim o extrato lixiviado e o extrato não lixiviado. Para caracterização das PCl's foram usadas amostras de $5 \mathrm{~g}$ de PCl's numa relação sólido/líquido de 1/20 durante um período de tempo de 24 horas a temperatura ambiente. $[9,10]$.

$\rightarrow \mathrm{Na}$ segunda etapa a fração não solubilizada, que ficou retida no papel filtro, foi submetida a uma nova lixiviação com ácido nítrico numa relação sólido/líquido de 1/5 durante 24 horas a temperatura ambiente. $O$ objetivo da digestão em ácido nítrico foi verificar a presença de prata ou outros metais remanescentes no extrato lixiviado resultante da primeira digestão.

Os extratos lixiviados tanto da água régia como do ácido nítrico foram analisados no ICP-OES com o objetivo de determinar as concentrações de metais presentes em cada um dos extratos solubilizados. Já o extrato não solubilizado foi destinado ao ensaio de perda ao fogo.

\subsection{Ensaio de Perda ao Fogo}

O ensaio de perda ao fogo foi realizado com o objetivo de quantificar a fração polimérica presente nas PCl's, para isso foi colocada uma alíquota de $1 \mathrm{~g}$ da fração não solúvel resultante da digestão ácida em navículas cerâmicas e levadas a um forno tipo mufla a temperatura de $800^{\circ} \mathrm{C}$ durante $1 \mathrm{~h}$.

A fração volátil corresponde ao material polimérico e foi calculada pela diferença entre a massa inicial e a final, e o restante equivale à fração inorgânica a qual representa a quantidade de materiais cerâmicos. 


\subsection{Análises Químicas}

Para determinar a quantidade de metais presentes nas PCl's. foram feitas análises químicas das frações solubilizadas resultantes da lixiviação em água régia e em ácido nítrico. A técnica empregada foi espectrometria de emissão atômica por plasma acoplado ICP-OES. Foram analisados os seguintes metais: prata, alumínio, ouro, bário, cálcio, cádmio, cobalto, cobre, ferro, índio, magnésio, manganês, níquel, chumbo, platina, estanho, estrôncio e zinco.

\section{RESULTADOS E DISCUSSÃO}

\subsection{Análises Granulométrica}

A distribuição do tamanho das partículas das PCls estudadas está apresentada na Figura 2.

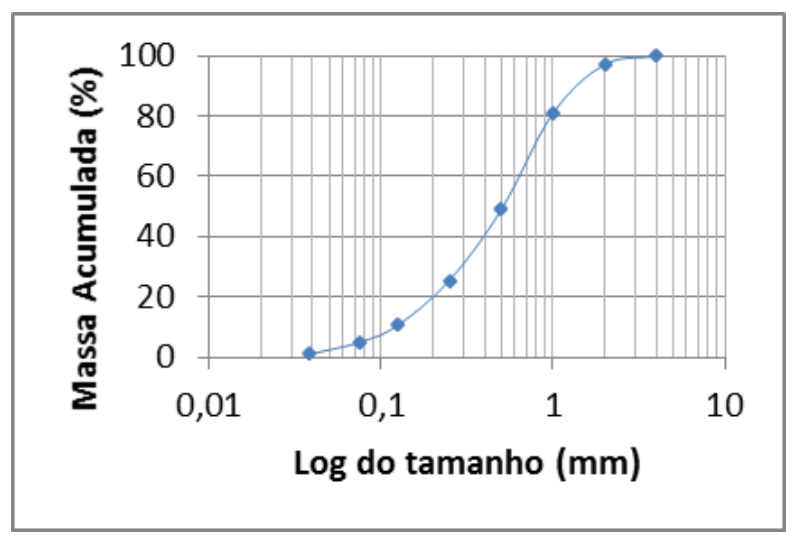

Figura 2. Análise do Tamanho de Partícula

Murugan et al. [11] observou que o metal não estava desassociado dos materiais poliméricos e cerâmicos quando a granulometria apresentava-se $>0,125 \mathrm{~mm}$. E apenas $20 \%$ do material analisado possui granulometria maior ou igual a $0,1 \mathrm{~mm}$ (Figura 2).

Por outro lado, segundo Zhang e Forssberg [12], é relativamente fácil liberar os compostos presentes nos resíduos eletrônicos já que esses estão ligados por fixação, soldagem, inserção ou empacotamento e apresentam ligações fracas em suas interfaces. Além disso, partículas abaixo de $2 \mathrm{~mm}$ as partículas metálicas estão completamente liberadas [13].

Assim, como $97 \%$ das partículas são menores que $2 \mathrm{~mm}$, a etapa de cominuição foi satisfatória e, tem como objetivo principal, aumentar a área de contato entre os materiais e os subprodutos da biolixiviação.

\subsection{MEV/EDS}

Dentre um lote de amostras analisadas no MEV, verificou-se a presença de dois tipos diferentes de PCls. Assim, optou-se por apresentar as micrografias de apenas duas das placas analisadas, uma de cada modelo (Figura 3 ). 

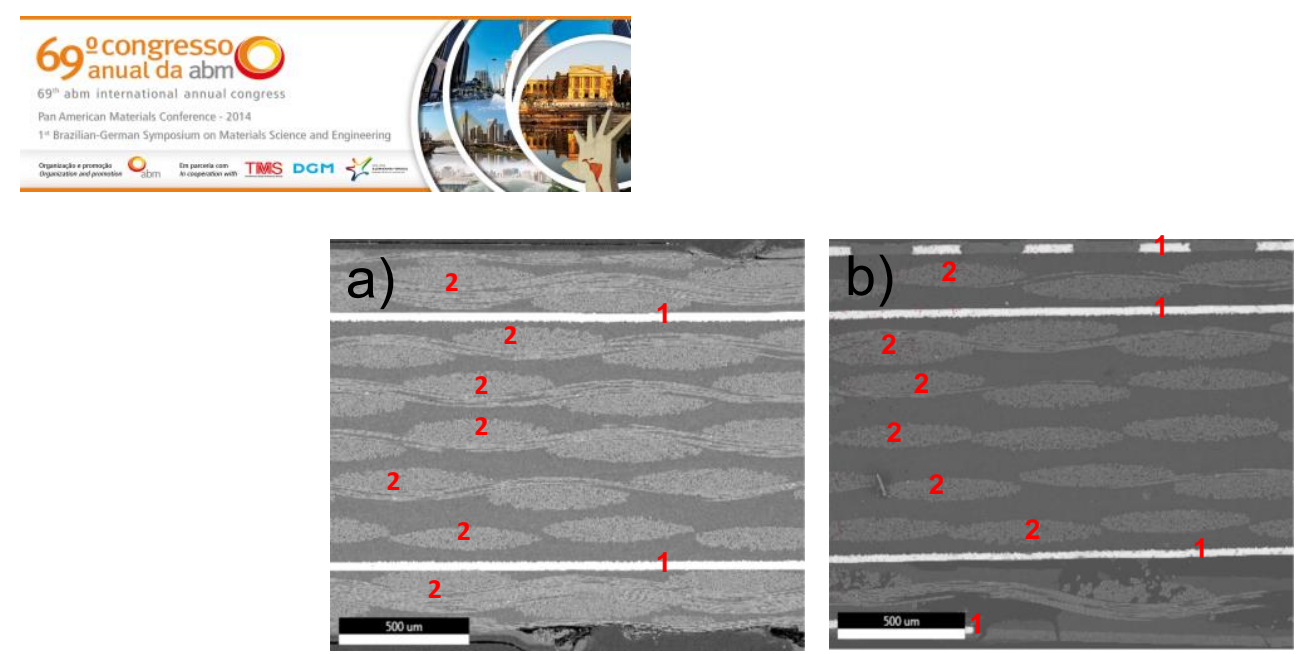

Figura 3. Imagens de elétrons retroespalhados da placa de circuito impresso: a) doublelayer; b) multilayer;

Pela análise das imagens obtidas no MEV/EDS, verificou-se que as placas utilizadas neste estudo podem ser doublelayer (Figura 2, a), isto é, apresentam duas camadas de cobre (ponto 1) ou multilayer (Figura 3, b), que apresentam quatro camadas de cobre (ponto 1).

O ponto 2 representa fibras de vidro. Isso concluiu-se pela análise de EDS pontual, que demonstrou a presença de cálcio e silício nesses pontos

\subsection{Composição das Placas de Circuito Impresso}

Para determinar a composição das PCl's foram feitos ensaios de lixiviação em meio ácido seguidos de ensaios de perda ao fogo.

Os ensaios de lixiviação permitiram quantificar a fração metálica das PCl's, a qual corresponde à somatória das frações solubilizadas obtidas em cada uma das etapas. Na lixiviação com água regia o conteúdo de material metálico foi de 35,6\% enquanto na lixiviação com ácido nítrico o valor obtido foi menor de $0,05 \%$, para um total de $35,65 \%$ de fração metálica presente nas amostras de PCl's.

A baixa presença de metais após lixiviação em ácido nítrico indicou que a maioria dos metais presentes nas PCl's foram solubilizados na primeira etapa da digestão em água regia.

O ensaio de perda ao fogo foi empregado para determinar a fração volátil e a não volátil, sendo que a fração volátil $(27,2 \%)$ representa a porcentagem de material polimérico presente nas PCl's, enquanto que a fração não volátil $(37,2 \%)$ representa a porcentagem de material cerâmico. Na figura 4 é apresentada a composição das placas de PCl's.

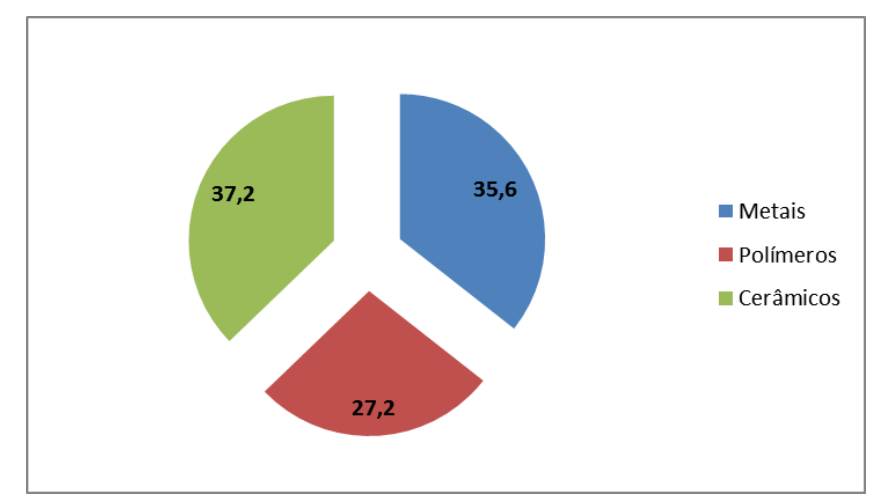

Figura 4. Composição das Placas de Circuito Impresso (\%).

* Contribuição técnica ao 69 Congresso Anual da ABM - Internacional e ao 14ํㅡㄹ ENEMET - Encontro Nacional de Estudantes de Engenharia Metalúrgica, de Materiais e de Minas, 21 a 25 de julho de 2014, São Paulo, SP, Brasil. 


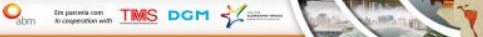

As análises químicas realizadas com os extratos lixiviados da digestão em meio ácido indicaram os elementos presentes nas PCl's e a concentração de cada um deles.

Na primeira etapa da digestão em meio ácido (água régia), foi lixiviado $99,9 \%$ dos metais presentes. As concentrações encontradas para cada um dos elementos estão apresentadas na figura 5 .

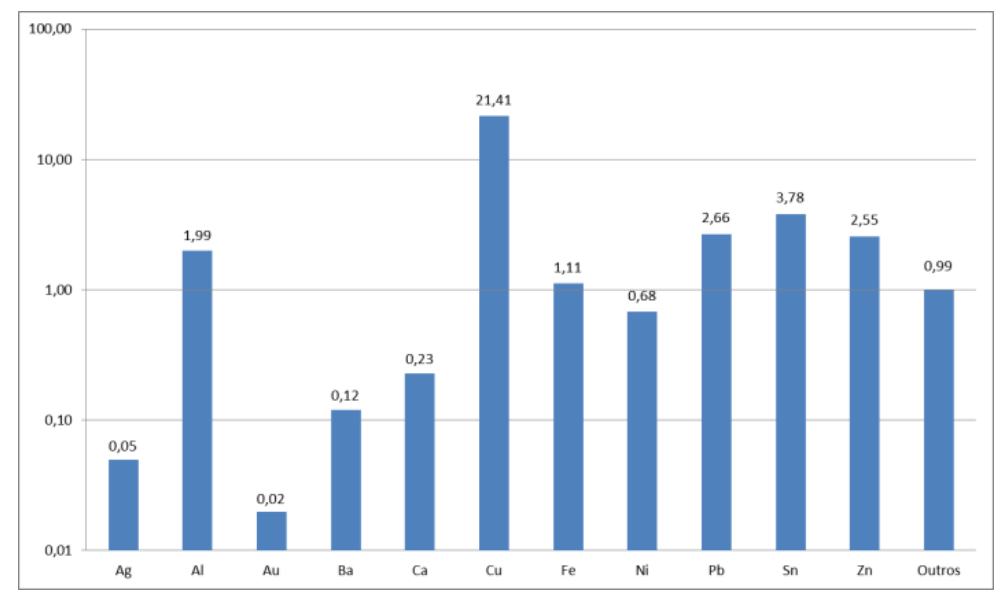

Figura 5. Composição da fração metálica (\% em massa).

Podemos observar que o cobre foi o metal que apresentou maior porcentual em massa $(21,4 \%)$.

Os outros metais analisados podem ser divididos em três grupos de acordo à ordem de grandeza. No primeiro grupo se encontram o estanho o chumbo e o zinco com valores de $3,78 \% ; 2,66 \%$ e $2,55 \%$, respectivamente.

No segundo grupo tem-se alumínio e ferro que apresentam concentrações de 1,99\% e $1,11 \%$, respectivamente.

$\mathrm{E}$, no último grupo se encontram metais com porcentual menor que $1 \%$, tais metais são a prata $(0,05 \%)$, o ouro $(0,02 \%)$ e o níquel $(0,68 \%)$.

Os resultados das análises químicas do extrato solubilizado da lixiviação em ácido nítrico mostraram que os metais remanescentes da primeira lixiviação equivalem a $0,05 \%$ em massa do total dos metais presentes.

Não foram encontrados metais tóxicos que podem afetar as bactérias como Cádmio e arsênio. Estes metais podem ser encontrados em circuitos eletrônicos presentes nas PCls e podem ser inibidores de crescimento ou até agentes bactericidas.

\section{CONCLUSÃO}

Com os resultados obtidos no presente trabalho podemos concluir que a lixiviação em ácido nítrico após água régia, não representa nenhuma vantagem na caracterização das PCl's, pois a primeira lixiviação mostrou eficiência de 99,9\% na solubilização dos metais presentes. A caracterização das placas estudadas mostrou que $35,6 \%$ da sua composição corresponde a metais, sendo que o cobre é o material que se encontra em maior quantidade $(21,4 \%)$.

Podem ser encontrados também outros metais em pequenas quantidades como estanho, zinco e chumbo. O chumbo encontrado nas placas deve-se ao fato de serem placas antigas, uma vez que atualmente as PCls são lead free, ou seja, não apresentam chumbo em sua composição. 
Pelas análises do microscópio eletrônico de varredura, conclui-se duas das placas são multi-layer, apresentando mais que duas camadas de cobre.

As PCls estudadas não apresentam componetes potencialmente tóxicos para as cepas bacterianas utilizadas em processos de biloxiviação motivo pelo qual a biolixiviação pode ser uma alternativa na recuperação dos metais presentes.

\section{Agradecimentos}

Os autores agradecem o suporte financeiro da CNPq, da Capes e do Santander pelas bolsas concedidas aos alunos participantes do presente trabalho.

\section{REFERENCIAS}

1 Andrade R. Caracterização e classificação de placas de circuito impresso de computadores como resíduos sólidos [dissertação de mestrado]. Campinas: Universidade Estadual de Campinas, 2002.

2 Guo Q, Yue X, Wang M, Liu Y. Pyrolisis of scrap printed circuit board plastic particles in a fluidized bed. Powder Technology, 2010; 198: 422-428.

3 Jie G, Ying-Shun L, Mai-Xi L. Product characterization of waste printed circuit board by pyrolysis. Journal of Analytical and Applied Pyrolysis, 2008; 83: 185-189.

4 Yamane HY. Recuperação de metais de placas de circuito impresso de computadores obsoletos através de processo biohidrometalúrgico [tese de doutorado]. São Paulo: Escola Politécnica da Universidade de São Paulo, 2012

5 Menetti RP. Recuperação de metais preciosos a partir de sucata eletrônica [trabalho de conclusão de curso]. São Paulo: Escola Politécnica da Universidade de São Paulo, 1996.

6 Moraes VT. Recuperação de metais a partir do processamento mecânico e hidrometalúrgio de placas de circuito impresso de celulares obsoletos [tese de doutorado]. São Paulo: Escola Politécnica da Universidade de São Paulo; 2011

7 Urenha LC. Metodologia para pesquisas de lixiviação bacteriana [dissertação de mestrado]. São Paulo: Escola Politécnica da Universidade de São Paulo, 1991.

8 Amostragem de resíduos sólidos Sampling of solid waste. ABNT: Associação Brasileira de Normas Técnicas.

9 Park YJ, Fray DJ. Recovery of High Purity Precious Metals from Printed Circuit Boards. Journal of Hazardous Materials, 2009; 164: 1152-1158.

10 Yamane LH, de Moraes VT, Espinosa DC, Tenório JA. Recycling of WEEE: Characterization of spent printed circuit boards from mobile phones and computers. Waste Manag., 2011; 31, 2553-2558.

11 Murugan RV, Bharat S, Deshpande AP, Varughese S, Haridoss P. Milling and Separation of the multi-component printed circuit materials and the analusis of elutriation based on a single particle model. Powder Technology; 183: 169-176.

12 Zhang S, Forssberg E, Intelligent liberation and classification of electronic scrap. Powder Technology, 105, 295-301.

13 Zhang S, Forssberg E. I Mechanical separation-oriented characterization of electronic scrap. Resources, Conservation and Recycling. 1997;21:247-269.

* Contribuição técnica ao 69ํㅡㄹ Congresso Anual da ABM - Internacional e ao 14º ENEMET - Encontro Nacional de Estudantes de Engenharia Metalúrgica, de Materiais e de Minas, 21 a 25 de julho de 2014, São Paulo, SP, Brasil. 